\title{
Perencanaan ruang terbuka hijau sebagai penampung burung di kawasan pesisir Pantai Lima, Mengwi, Badung
}

\author{
I Putu Agus Octa Bryantara ${ }^{1}$, Lury Sevita Yusiana ${ }^{1 *}$, Luh Putu Eswaryanti Kusuma Yuni² \\ 1. Prodi Arsitektur Pertamanan, Fakultas Pertanian, Universitas Udayana, Indonesia 80236 \\ 2. Prodi Biologi, Fakultas Matematika dan Ilmu Pengetahuan Alam, \\ Universitas Udayana, Indonesia 80361
}

*Email: lury.yusiana@unud.ac.id

\begin{abstract}
Green open space planning as a bird sink in Lima coastal area, Mengwi, Badung. The Reduction of bird breeding habitat caused the bird population decreases every year. Birds have its ecological functions as part of the food chain and ecosystem balancer, bioindicators of environmental change, help pollinate the plants and as a pest predators. The survey method used is observation, interviews and literature reviews. The planning stages refer to Simond (1983) consist of objectives, inventory, analysis, synthesis and planning. The purpose of Lima Coastal Areas Planning is as a sink area. The results of data analysis showed the suitability of the Lima Coastal area as a green open space bird habitat with an area of 18,000 m2 has various types of birds such as turtle birds, erasian sparrows, peking bondol, cow swallow, turtledoves, cucumber merbah, rice kareo birds, rice fields and heron. Green space planning for bird habitats in the Lima Coastal area is arranged based on the concept of green open space as a sink area for birds. Spatial planning based on its function is divided into storage areas, transitions, corridors and education areas. The circulation systems are the circulation of birds from the source area to the sink area and the human circulation. Vegetation Planning also needed as a source of feed, nest and breed. Site Planning can be prepared as a bird green space sink in accordance with the sink and source concept so that it can be developed into a core area of sink protection, transition, corridor and education area.
\end{abstract}

Keywords: bird, bird habitat planning, green open space, sink, source

\section{Pendahuluan}

Indonesia adalah wilayah yang memiliki keragaman jenis burung yang tinggi, bahkan merupakan negara keempat dengan keanekaragaman burung tertinggi di dunia setelah Kolombia, Peru, dan Brazil (Mardiastuti dkk., 2008). Berdasarkan data Burung Indonesia tahun 2015, Indonesia memiliki 1.672 jenis burung dan sekitar 427 jenis diantaranya merupakan jenis endemik. Berdasarkan data dari IUCN (International Union for Conservation of Nature), saat ini tercatat, sekitar 22 jenis burung yang berstatus kritis (Critically Endangered), 34 jenis berlabel genting (Endangered), dan 81 jenis digolongkan rentan (Vulnerable) (Rahmadi, 2016). Status tersebut membuktikan bahwa kepedulian terhadap satwa burung masih sangat kurang. Pesisir Pantai Lima sebagai salah satu area yang masih terdapat satwa burung harus diperhatikan sehingga keberadaan satwa burung pada PPL tetap terjaga. Burung memiliki fungsi ekologi sebagai bagian dari rantai makanan dan penyeimbang ekosistem, bioindikator perubahan lingkungan, membantu penyerbukan tanaman, sebagai predator hama (Direktorat Perlindungan dan Pengawetan Alam, 1983) oleh sebab itu, Ruang Terbuka Hijau (RTH) dapat menjadi area potensial untuk perlindungan, peningkatan jumlah dan jenis burung.

Data dari LIPI tahun 2018 dalam kurun waktu tahun 2000 sampai saat ini, di Indonesia terjadi penurunan populasi burung di habitat alamnya lebih dari 50 persen. Menurut Wiens dan Rottenberry (1981), permasalahan yang ada pada Pesisir Pantai Lima (PPL) dari segi habitat burung yaitu jumlah burung yang dihasilkan pada area sumber melebihi daya tampung habitat setempatnya menyebabkan akan terjadi penyebaran keluar populasi sumber tersebut. PPL merupakan kawasan yang masih terjaga kealamiannya sehingga banyak terdapat satwa burung. PPL sebagai satu-satunya area penampung (sink) dari area persawahan yang dianggap sebagai area sumber (source). Masih belum adanya kegiatan pelestarian keanekaragaman hayati, termasuk untuk pelestarian burung sehingga perlu adanya perhatian khusus. Bila dibiarkan begitu saja populasi burung yang ada di PPL akan terancam hilang. Pesisir Pantai Lima menjadi 
salah satu bagian kecil dari perlunya upaya pelestarian dan perlindungan burung, sehingga diperlukan area penampung sebagai tempat burung berkembang biak dan berlindung. Terletak di Jalan Babadan Desa Pererenan, Kecamatan Mengwi, Kabupaten Badung. Permasalahan yang terdapat pada PPL dapat diatasi dengan merencanakan RTH penampung burung sebagai suatu ruang dengan populasi penampung (sink population) (Wiens dan Rottenberry, 1981). Perencanaan RTH habitat burung dapat menjaga populasi burung yang ada, masyarakat dapat mengetahui dan mempelajari berbagai jenis satwa burung yang keberadaanya mulai terancam dan memberikan ruang terhadap masyarakat untuk menikmati keberadaan burung. Sehingga penelitian dilakukan bertujuan untuk mengindentifikasi jenis satwa burung dan kondisi biofisik termasuk keragaman jenis satwa burung di Pesisir Pantai Lima Mengwi, Badung dan merencanakan ruang terbuka hijau penampung burung (sink) di Pesisir Pantai Lima Mengwi, Badung, karena kawasan PPL merupakan area penampung satu-satunya yang ada.

2. Metode

\subsection{Lokasi dan Waktu Penelitian}

Penelitian dilakukan di kawasan Pesisir Pantai Lima (PPL) terletak di Jalan Babadan Desa Pererenan, Kecamatan Mengwi, Kabupaten Badung Provinsi Bali dengan luas wilayah kawasan sekitar 18,000 m². Penelitian ini dilaksanakan pada bulan Februari 2018 sampai dengan Juni 2018.

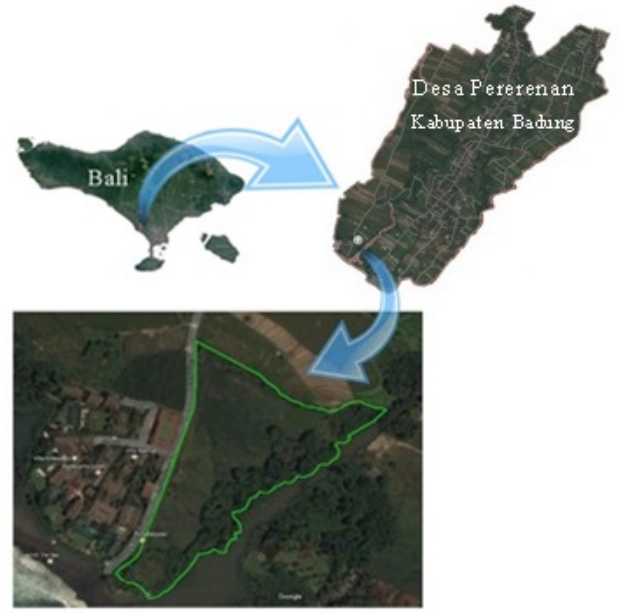

Gambar 1. Peta Lokasi Penelitian

\subsection{Alat dan Bahan}

Alat yang digunakan dalam penelitian ini adalah Kamera, Laptop, Software desain (Auto CAD, Skatechup, Lumion, dan Adobe Photoshop), pengelolaan data (Microsoft Excel).

\subsection{Metode Penelitian}

Metode penelitian yang digunakan adalah metode survei dengan teknik observasi, wawancara dan studi pustaka. Observasi dilakukan dengan cara membuat rekaman suara, foto maupun video serta catatancatatan yang dibuat langsung untuk mengetahui kondisi biofisik tapak. Metode identifikasi burung dalam penelitian ini menggunakan alat seperti binokular dan kamera untuk mengamati dan menghasilkan foto yang dapat diidentifikasi sesuai buku panduan burung Jawa dan Bali menurut Mackinnon et al., (2010). Data grafik pengamatan burung perhari digunakan untuk menentukan apakah perlu pengamatan lebih lanjut sehingga didapat data jenis burung apa saja yang ada pada tapak. Selain itu juga dilakukan wawancara terhadap pihakpihak terkait serta mencari data-data yang berhubungan dengan penelitian, baik data yang bersumber dari buku, jurnal, makalah maupun media internet. Tahapan perencanaan terdiri dari tujuan, inventarisasi, analisis, sintesis dan perencanaan (Simond, 1983). Menurut Wiens dan Rotenberry (1981), tapak yang direncanakan dianggap sebagai suatu ruang dengan populasi penampung (sink population) dengan luas minimal 401,3 $\mathrm{m}^{2}$ dan memiliki area populasi sumber (source) dengan luas lebih dari 50 ha. Keterkaitan metode Wiens dan Rottenberry dengan Simond yaitu tujuan awal perencanaan disesuaikan dengan metode Wiens dan Rottenberry dengan merencanakan RTH habitat burung sebagia area penampung sehingga tahapan perencanaan selanjutnya sesuai dengan tujuan perencanaan yang ada. 


\section{Hasil dan Pembahasan}

\subsection{Tujuan Perencanaan Tapak}

Tujuan perencanaan Pesisir Pantai Lima (PPL) adalah RTH sebagai area penampung burung (sink). Hasil penelitian dari Khaerunnisa, (2013) dibutuhkan area minimum seluas 401,3 $\mathrm{m}^{2}$ untuk keseluruhan area penampung. Luas area pada tapak adalah $18,000 \mathrm{~m}^{2}$ sehingga memenuhi kriteria luas sebagai area penampung. Berdasarkan kriteria RTH sebagai tempat bersarang menurut Khaerunnisa (2013), mengenai luas yang dibutuhkan untuk satwa burung yang ada yaitu area sumber memiliki luas lebih dari 50 hektar sebagai daerah bertelur sedangkan area penampungan memiliki luas 401,3 $\mathrm{m}^{2}$ sebagai daerah berlindung dan berkembang biak. Tapak ini berfungsi sebagai satu-satunya area penampung yang ada. Potensi area sumber dapat dilihat pada Gambar 2.

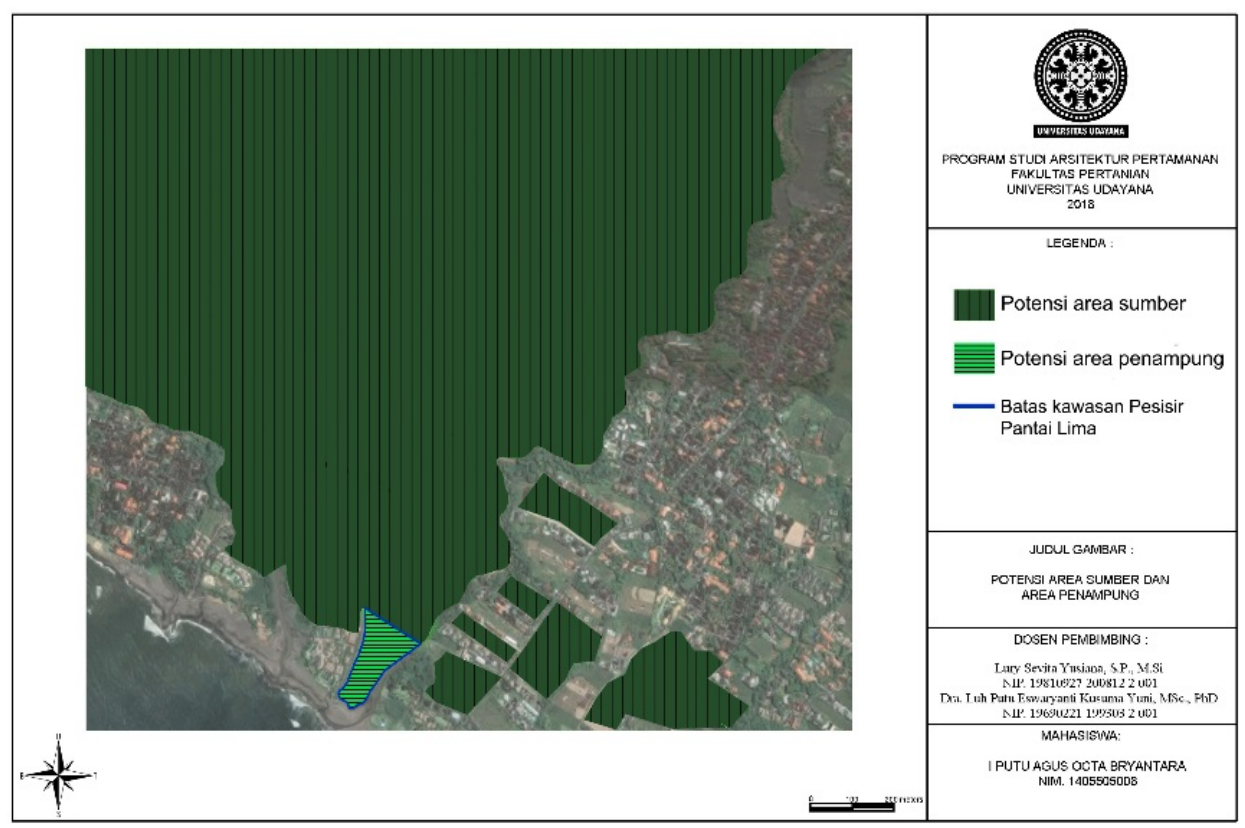

Gambar 2. Potensi Area Sumber

\subsection{Inventarisasi}

\subsubsection{Kondisi Umum Tapak}

Tapak penelitian berada di Pesisir Pantai Lima dan secara administratif terletak di Desa Pererenan, Kecamatan Mengwi, Kabupaten Badung Provinsi Bali. Secara geografis, terletak pada 8038'57,6"LS dan 115007'11,6"BT, tapak ini merupakan milik perorangan dan telah dijual kepada investor. Tapak dibatasi oleh muara sungai di bagian timur, di bagian barat dibatasi oleh Jalan Babadan dan Pantai Lima Estate, di bagian utara berbatasan dengan area persawahan sedangkan di sebelah selatan berbatasan dengan Pura Babadan dan Pantai Lima. Tapak terdiri dari semak, pepohonan dan didominasi oleh rerumputan.

\subsubsection{Kondisi Biofisik Tapak}

Tapak ini memiliki luas area 17,451 $\mathrm{m}^{2}$ atau 18,000 $\mathrm{m}^{2}$ dengan kisaran elevasi (ketinggian tanah dari permukaan laut) enam meter dari permukaan laut dengan slope kemiringan lahan 0-3\%. Tapak berada pada daerah pantai dengan curah hujan per tahun mencapai $215 \mathrm{~mm}$ dan suhu rata-rata 27,50 C (Data Stasiun Geofisika Sanglah tahun 2008-2017). Saluran drainase di tapak yaitu drainase alamiah (sungai) dan drainase terbuka buatan. Vegetasi yang ada pada tapak seperti Waru (Hibiscus tiliaceus), Pandan Duri (Pandanus tectorius) dan Rumput Paitan (Axonopus compressus). Pasang air laut tertinggi terjadi pada bulan Maret-Juni dengan ketinggian 2,7 m sedangkan surut terendah terjadi pada bulan Januari-Desember dengan ketinggian surut terendah 0,0 m (TNI Angkatan Laut, 2017). Satwa yang ada pada tapak yaitu satwa ekosistem terestrial seperti Sapi, Jangkrik dan burung sedangkan satwa ekosistem akuatik seperti Ikan Tembakul (Oxudercinae), Kerang Teritip (Cirripedia), Kerang Melanoides (Melanoides sp). Jenis satwa burung yang ada seperti Burung Tekukur (Spilopelia chinensis), Burung Perkutut (Geopelia striata), Gereja (Passer montanus), Bondol (Lonchura puntulata) sebagai pemakan biji-bijian sedangkan Cerukcuk (Pycnonotus goiavier) sebagai 
pemakan buah dan jenis burung lainnya sebagai pemakan serangga dan hewan invertebrate seperti Kuntul (Ardaeidae), Walet (Collocalia esculanta), Kareo Padi (Amaurornis phoenicurus), dan Blekok Sawah (Ardeola speciose).

\subsection{Analisis dan Sintesis}

Merujuk konsep Wiens dan Rottenberry yaitu RTH yang direncanakan dianggap sebagai suatu ruang dengan populasi penampung (sink population). Populasi sumber (source population) merupakan populasi yang menempati habitat yang sesuai untuk berkembang biak sedangkan area penampung (sink) merupakan daerah dengan sedikit gangguan dan mencakup wilayah cukup luas dan aman bagi burung. Tapak ini dapat dikembangkan sebagai area penampung (sink) burung yang berpindah dari area sumber (source) (Wiens dan Rotenberry, 1981). Area di sekitar tapak dianggap sebagai area potensi sumber karena memiliki peran penting dalam ketersediaan jenis burung. Jalur hijau dan koridor air/saluran drainase difungsikan sebagai koridor penghubung antara area sumber dan penampung. Jenis tanah pada tapak tergolong subur sehingga sangat potensial untuk perencanaan RTH penampung burung. Vegetasi yang potensial dikembangkan pada tapak sesuai dengan jenis tanahnya yaitu vegetasi hutan hujan tropis yang merupakan penyedia pakan melimpah bagi burung. Jenis pakan yang dominan dihasilkan tanaman adalah jenis buah, biji-bijian dan pengundang serangga sehingga jenis burung yang berpotensi dikembangkan adalah burung pemakan buah, biji dan serangga

\subsection{Perencanaan}

\subsubsection{Konsep Dasar}

Konsep dasar dalam penelitian ini adalah RTH sebagai habitat burung berupa area penampung (sink). Berdasarkan hasil sintesis, kawasan PPL dapat dikembangkan sebagai area penampung (sink) untuk bersarang, bertelur, mencari makan dan bermain. Jenis yang terdapat pada tapak yaitu burung pemakan biji, buah dan serangga menjadikan lanskap ruang terbuka hijau penampung burung sebagai area penampung burung pemakan biji, buah dan serangga.

\subsubsection{Pengembangan Konsep}

\subsubsection{Konsep Ruang}

Konsep ruang dikembangkan berdasarkan fungsi menjadi ruang pelestarian dan ruang pemanfaatan. Ruang pelestarian meliputi area inti penampung, transisi dan koridor, sedangkan ruang pemanfaatan meliputi area edukasi. Koridor berdasarkan bentuknya yaitu koridor ruang terbuka (koridor hijau dan koridor air). Konsep pembagian ruang ini dimaksudkan agar pergerakan burung lebih terarah. Konsep ruang berdasarkan fungsinya dapat dilihat pada gambar 3.

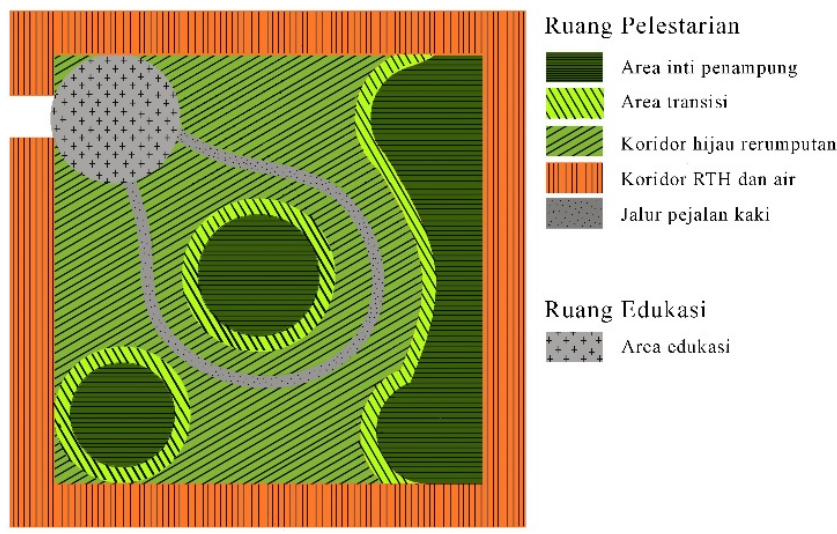

Gambar 3. Konsep Ruang Berdasarkan Fungsinya

\subsubsection{Konsep Sirkulasi}

Konsep sirkulasi dalam perencanaan RTH sebagai penampung burung adalah sirkulasi terbatas bagi manusia dan sirkulasi tidak terbatas bagi burung. Sirkulasi manusia direncanakan memiliki fungsi untuk menikmati, mengamati keberadaan burung dan membatasi pergerakan manusia. Sirkulasi manusia dari area edukasi mengelilingi kawasan dan kembali menuju area edukasi dengan dibatasi area hijau rerumputan dan transisi agar tidak mengganggu keberadaan burung. Sirkulasi burung pada area sink bebas menuju ruang 
yang ada pada tapak sesuai aktivitas alaminya di alam liar dan tidak dibatasi peregerakannya. Gambar 4 merupakan konsep sirkulasi manusia dan burung.

\subsubsection{Konsep Vegetasi}

Konsep vegetasi adalah area penampung burung yang difungsikan untuk bersarang, sumber pakan, dan berkembang biak. Berdasarkan faktor ekosistem vegetasi area penampung dibedakan untuk burung pemakan buah, biji dan serangga. Vegetasi yang diterapkan pada tapak berdasarkan (Leedy, 1978) dapat dibedakan menjadi enam jenis vegetasi, yaitu: tanaman konifer, semak, rumput, gabungan tanaman, tanaman tepi air dan tanaman peneduh.

\subsubsection{Konsep Aktivitas}

Konsep aktivitas diperuntukkan bagi manusia berupa aktivitas edukasi kehidupan burung. Aktivitas yang direncanakan pada tapak dimanfaatkan sebagai wadah edukasi melalui aktivitas sosialisasi, pengamatan burung (birdwatching), informasi (signage).

\subsubsection{Perencanaan RTH}

\subsubsection{Tata Ruang Terbuka Hijau}

Rencana ruang secara makro merupakan hubungan antara sink dan source sedangkan secara mikro merupakan hubungan antara area-area sink. Sink terbagi menjadi dua area yang berbeda yaitu area bersarang dan area transisi. Sink memiliki fungsi utama sebagai tempat bersarang dan sumber pakan utama. Koridor merupakan penghubung antar area penampung, dan area penampung dengan source. Koridor dibuat berkelanjutan dengan tujuan mengarahkan burung ke area penampung. Penggunaan koridor hijau bertujuan agar koridor penghubung tidak terputus dan dapat berfungsi sebagai pengarah burung ke area penampung. Area edukasi sebagai tempat masyarakat melakukan sosialisasi, pengamatan dan difungsikan untuk mendukung keberadaan jenis satwa burung, mengingat bahwa prilaku sosial manusia mulai terbentuk dari usia dini. Gambar 4 merupakan ilustrasi tata ruang perencanaan RTH penampung burung pada tapak. Rencana tata ruang dapat dilihat pada gambar 5 .

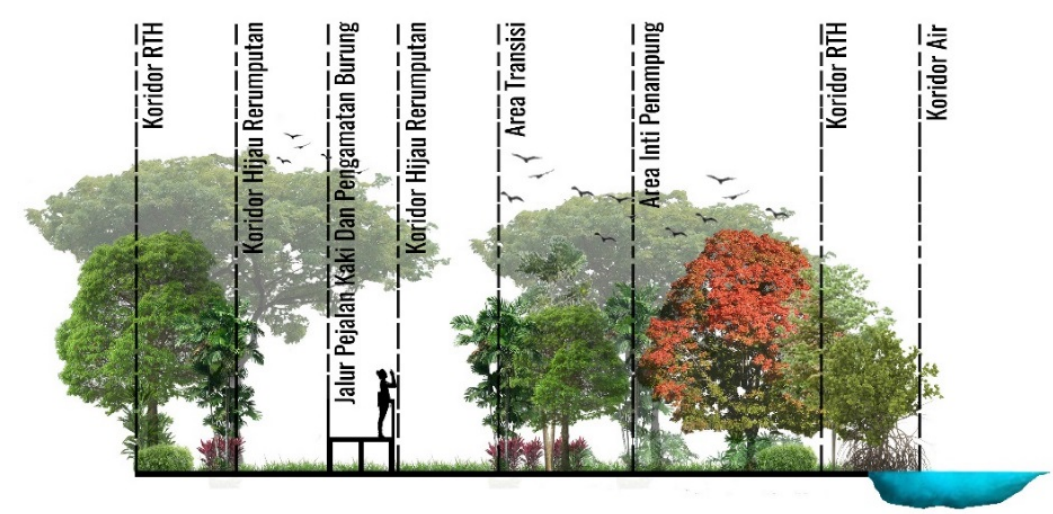

Gambar 4. llustrasi Tata Ruang RTH 


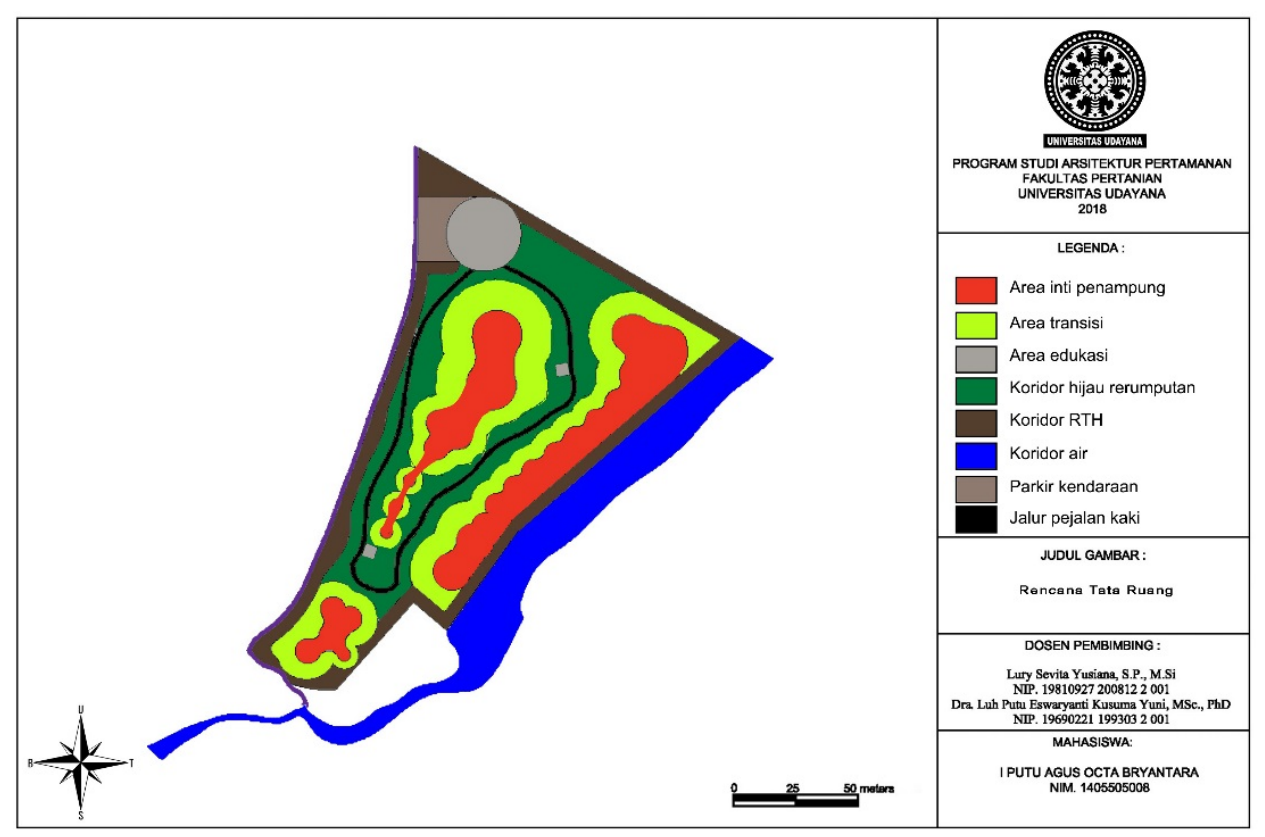

Gambar 5. Rencana Tata Ruang

\subsubsection{Tata Sirkulasi}

Model sirkulasi manusia pada perencanaan RTH sebagai penampung burung pada tapak menggunakan pola sirkulasi membentuk jalur melingkar memutar pada pedestrian pejalan kaki. Pola sirkulasi ini memudahkan pengguna mengelilingi kawasan untuk menikmati keberadaan burung dan melakukan pengamatan tanpa mengganggu keberadaan burung yang ada. Sirkulasi burung berupa koridor RTH dan air serta koridor hijau sebagai penghubung menuju area penampung. Koridor sebagai penghubung perpindahan atau sirkulasi spesies burung dari area sumber (source) ke area penampungan (sink). Rencana tata sirkulasi dapat dilihat pada gambar 6 .

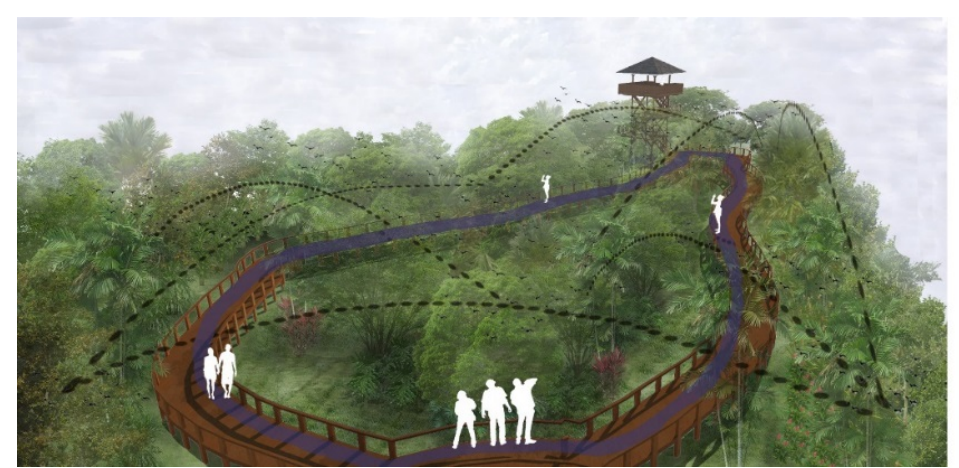

Keterangan:

c....... Sirkulasi Burung Sirkulasi Manusia

Gambar 6. llustrasi Sirkulasi Manusia dan Burung

\subsubsection{Tata Vegetasi}

Jenis vegetasi direncanakan memiliki keragaman yang tinggi. Hal ini supaya jenis burung eksisting lainnya tetap akan mendapat suplai makanan sehingga burung yang ada di kawasan ini akan lebih beragam. Pada area sink dibagi menjadi tiga jenis vegetasi sesuai jenis burung yang ada yaitu pemakan buah, biji, dan serangga. Gambar 7 merupakan perencanaan tata vegetasi 


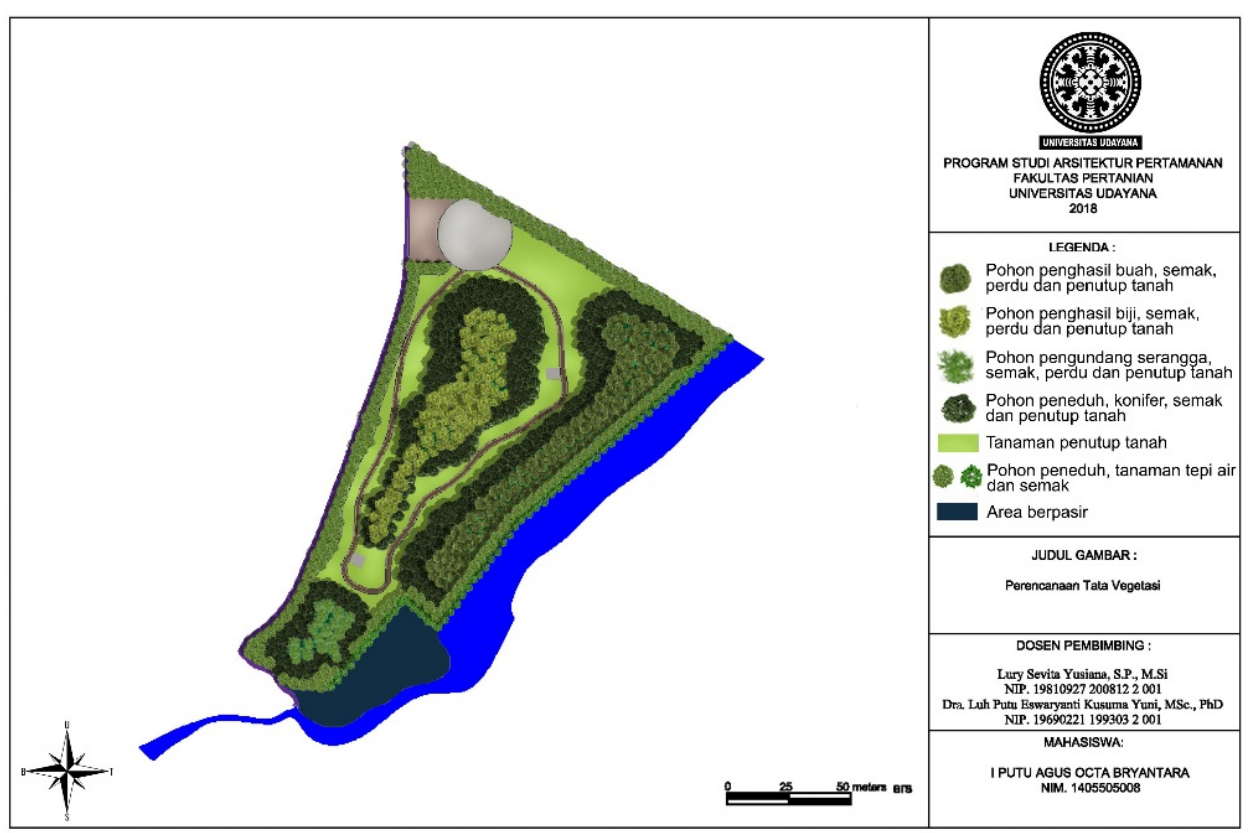

Gambar 7. Rencana Tata Vegetasi

\subsubsection{Keterkaitan Aktivitas dan Fasilitas}

Setiap ruang memiliki fungsi yang berbeda dan setiap fungsi menghadirkan kegiatan yang berbeda. Fasilitas disediakan untuk menunjang kegiatan yang direncanakan. Keterkaitan antara ruang, sub ruang, fungsi ruang, aktivitas dan fasilitas tersaji pada tabel 1.

Tabel 1. Keterkaitan Aktivitas dan Fasilitas

\begin{tabular}{|c|c|c|c|c|c|}
\hline No. & Ruang & Sub Ruang & Fungsi Ruang & Aktivitas & Fasilitas \\
\hline & & $\begin{array}{l}\text { Inti } \\
\text { penampung }\end{array}$ & $\begin{array}{l}\text { Sebagai area } \\
\text { penampung burung } \\
\text { dari gangguan dan }\end{array}$ & $\begin{array}{l}\text { Manusia: } \\
\text { tidak ada }\end{array}$ & $\begin{array}{l}\text { Manusia: } \\
\text { Tidak ada }\end{array}$ \\
\hline \multirow[t]{9}{*}{1.} & Pelestarian & & ancaman lainnya & Burung: & Burung: \\
\hline & & & $\begin{array}{l}\text { serta sebagai tempat } \\
\text { berkembang biak }\end{array}$ & $\begin{array}{l}\text { Berlindung dan } \\
\text { berkembang biak }\end{array}$ & $\begin{array}{l}\text { Tanaman } \\
\text { penghasil buah, } \\
\text { biji dan serangga }\end{array}$ \\
\hline & & Transisi & $\begin{array}{l}\text { Sebagai batas atau } \\
\text { tepi luar dari area } \\
\text { penampungan }\end{array}$ & $\begin{array}{l}\text { Manusia: Tidak } \\
\text { ada }\end{array}$ & $\begin{array}{l}\text { Manusia: } \\
\text { Tidak ada }\end{array}$ \\
\hline & & & & Burung: & Burung: \\
\hline & & & & $\begin{array}{l}\text { Beristirahat dan } \\
\text { mencari makan }\end{array}$ & $\begin{array}{l}\text { Tanaman } \\
\text { peneduh, semak, } \\
\text { konifer, dan } \\
\text { penutup tanah }\end{array}$ \\
\hline & & Koridor RTH & $\begin{array}{l}\text { Penghubung } \\
\text { perpindahan dan } \\
\text { sirkulasi burung dari }\end{array}$ & $\begin{array}{l}\text { Manusia: } \\
\text { Tidak ada }\end{array}$ & $\begin{array}{l}\text { Manusia: } \\
\text { Tidak ada }\end{array}$ \\
\hline & & & area sumber ke area & Burung: & Burung: \\
\hline & & & $\begin{array}{l}\text { penampung dan area } \\
\text { sumber satu ke area } \\
\text { sumber lain }\end{array}$ & $\begin{array}{l}\text { Mencari makan, } \\
\text { tidur, kawin dan } \\
\text { bersarang }\end{array}$ & $\begin{array}{l}\text { Tanaman } \\
\text { peneduh, } \\
\text { tanaman tepi air } \\
\text { dan semak }\end{array}$ \\
\hline & & $\begin{array}{l}\text { Koridor } \\
\text { hijau } \\
\text { rerumputan }\end{array}$ & $\begin{array}{l}\text { Penghubung } \\
\text { perpindahan antar } \\
\text { area penampungan } \\
\text { pada tapak dan }\end{array}$ & $\begin{array}{l}\text { Manusia: } \\
\text { Pengamatan } \\
\text { burung }\end{array}$ & $\begin{array}{l}\text { Manusia: } \\
\text { Jalur pedestrian, } \\
\text { menara } \\
\text { pengamatan, }\end{array}$ \\
\hline
\end{tabular}




\begin{tabular}{|c|c|c|c|c|c|}
\hline No. & Ruang & Sub Ruang & Fungsi Ruang & Aktivitas & Fasilitas \\
\hline & & & $\begin{array}{l}\text { sebagai area sirkulasi } \\
\text { manusia }\end{array}$ & & $\begin{array}{l}\text { gazebo } \\
\text { pengamatan }\end{array}$ \\
\hline 2. & Pemanfaatan & $\begin{array}{l}\text { Area } \\
\text { edukasi }\end{array}$ & $\begin{array}{l}\text { Kegiatan sosialisasi, } \\
\text { pengamatan dan } \\
\text { informasi (signage) }\end{array}$ & $\begin{array}{l}\text { Burung: } \\
\text { Bermain, mencari } \\
\text { makan } \\
\text { Manusia: } \\
\text { Penelitian, } \\
\text { pengamatan } \\
\text { burung }\end{array}$ & $\begin{array}{l}\text { Burung: } \\
\text { Tanaman } \\
\text { rerumputan, } \\
\text { pepohonan } \\
\text { Manusia: } \\
\text { Bangunan semi } \\
\text { terbuka, Parkir, } \\
\text { toilet }\end{array}$ \\
\hline
\end{tabular}

\subsubsection{Site Plan}

Gambar 8 merupakan peta site plan perencanaan RTH sebagai penampung burung pada tapak. Site plan merupakan gabungan dari perencanaan tata ruang, sirkulasi, vegetasi dan aktivitas. Perencanaan ruang berdasarkan fungsinya dibagi menjadi dua yaitu ruang pelestarian meliputi area inti penampung, transisi dan koridor sedangkan ruang pemanfaatan meliputi area edukasi seperti bangunan semi terbuka sebagai tempat sosialisasi, menara pandang, gazebo dan pedestrian sebagai tempat pengamatan burung. Perencanaan sirkulasi dibagi menjadi dua, yaitu sirkulasi manusia dan sirkulasi burung. Sirkulasi manusia yaitu mengelilingi kawasan dengan searah jarum jam atau sebaliknya sedangkan burung dihubungkan dengan koridor dari source menuju sink dan dari area inti menuju area inti lainnya. Perencanaan vegetasi sesuai dengan konsep ruang yaitu vegetasi area inti penampung, vegetasi transisi, vegetasi koridor dan rerumputan. Pada area sink dibagi menjadi tiga jenis vegetasi sesuai jenis burung yang ada yaitu pemakan buah, biji, dan serangga. Perencanaan aktivitas yang didukung dengan fasilitas pendukung seperti parkiran dan toilet 


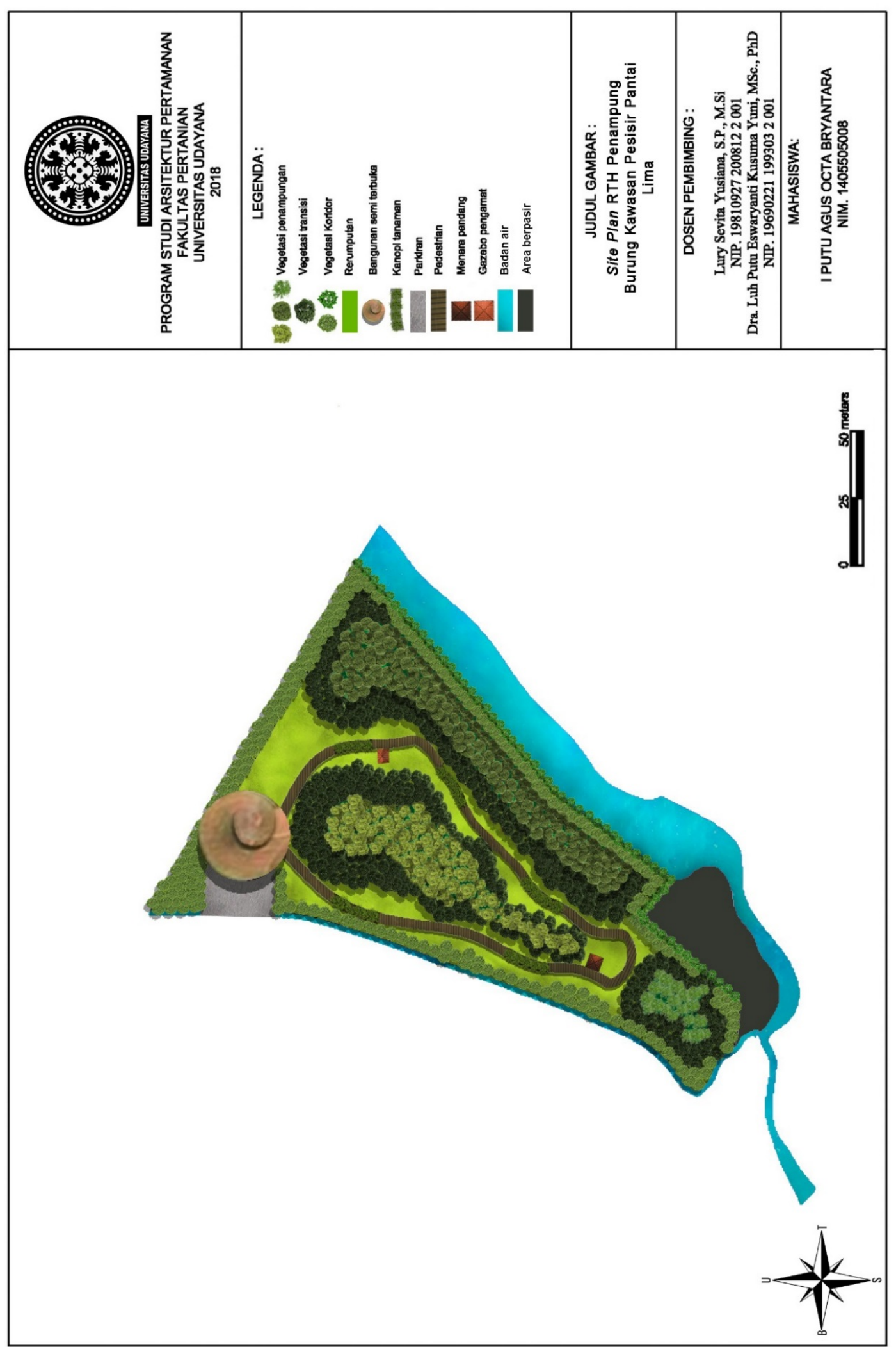

Gambar 8. Site Plan RTH sebagai penampung Burung 


\section{Penutup \\ 4.1 Simpulan}

Terdapat 11 jenis satwa burung di Pesisir Pantai Lima yang sudah teridentifikasi dan didominasi oleh burung pemakan buah, biji-bijian dan serangga seperti Burung Tekukur (Spilopelia chinensis), Burung Perkutut (Geopelia stritiata), Cerukcuk (pycnonotus goiavier), Kuntul (Ardeidae), Gereja (Passer montanus), Bondol (Lonchura puntulata), Walet (Collocalia esculanta), Kareo Padi (Amaurornis phoenicurus), dan Blekok Sawah (Ardeola speciosa). Potensi jenis burung yang ada dikembangkan sebagai RTH habitat burung sebagai area penampung. Potensi jenis vegetasi penghasil pakan biji-bijian, buah-buahan, dan pengundang serangga. Topografi dan tanah pada tapak memiliki kemiringan landai 0-3\% dan teridentifikasi termasuk jenis tanah latosol. Drainase yang ada adalah saluran drainase alami dan buatan. Kondisi iklim menunjukan bahwa suhu dan kelembaban di lokasi studi sesuai untuk satwa burung. Perencanaan pada tapak dapat disusun sebagai RTH habitat burung sebagai area penampung (sink), sesuai dengan konsep sink-source. Berdasarkan pengembangannya dapat dikembangkan menjadi area inti penampung, transisi, koridor dan area edukasi. Area inti penampung sebagai penampung burung dari area sumber. Tiap area dihubungkan dengan koridor dan area transisi.

\subsection{Saran}

Penelitian ini tidak ditemukan adanya jenis burung migrasi. Oleh karena itu, perlu diadakan penelitian lebih lanjut pada tapak untuk mengidentifikasi jenis burung migrasi yang ada pada tapak sehingga perencanaan ruang terbuka hijau penampung burung bisa menjadi area perlindungan penampung bagi jenis burung migrasi. Pemanfaatan yang jelas pada tapak saat ini belum ada, sehingga masyarakat memanfaatkannya sebagai tempat beternak sapi. Pengembangan selanjutnya pada PPL, investor bisa mengembangkan RTH penampung burung sebagai alternatif tempat wisata baru.

\section{Daftar Pustaka}

BMKG Ngurah Rai, Denpasar, Bali. 2018. Data Stasiun Geofisika Sanglah tahun 2008-2017. Denpasar, Bali. Burung Indonesia. 2015. Data Burung Indonesia. 2015

Direktorat Perlindungan dan Pengawetan Alam. 1983. Pedoman Teknik Inventarisasi Burung (Dasar-Dasar Umum) Proyek Pembinaan Kelestarian Sumberdaya Alam Hayati. Departemen Kehutanan dan Perkebunan. Bogor

Khaerunnisa, D. 2013. Perencanaan Ruang Terbuka Hijau Ekologis Sebagai Habitat Burung Di Kawasan Perumahan Bukit Cimanggu City. Skripsi (Tidak Dipublikasikan) Institut Pertanian Bogor.

Leedy, D.L. 1978. Planning Wildlife in Cities and Suburbs. Washington: U.S. Printing Government Office.

Mardiastuti, A., Y. A. Mulyani, J. Sugarjito, L. N. Ginonga, I. Maryanto, A. Nugraha dan Ismail. 1998. Teknik pengusahaan Burung Walet rumah, pemanenan sarang, dan penanganan pasca panen. Laporan Riset Unggulan Terpadu IV. Kantor Menteri Negara Riset dan Teknologi, Dewan Riset Nasional, Jakarta.

Rahmadi, R. 2016. Konservasi burung liar memang penting untuk ekosistem alam. http://www.mongabay.co.id/2016/02/12/konservasi burung liar memang penting untuk ekosistem alam.html. Diakses tanggal 2 juni2017 pukul 20.00 WITA

Rusilawati, S.K. 2002. Perencanaan Ruang Terbuka Hijau untuk Habitat Burung di Kawasan Permukiman Real Estat Bintaro Jaya Sektor 9 Tangerang. Skripsi (Tidak Dipublikasikan) Institut Pertanian Bogor.

Simond, J.O. 1983. Landscape Architecture. McGraw-Hill Book Co, NewYork.

TNI Angkatan Laut.2017. Daftar Pasang Surut Kepulauan Indonesia 2017. Dinas Hidro-Oseanografi TNI Angkatan Laut. Jakarta

Wiens, J.A. dan J.T. Rottenberry. 1981. Censusing and The Evaluation of Avian Habitat Occupancy. Dalam C.J. Ralph dan J.M. Scot. 1981. Testimating The Numbers of Terrestrial Birds. Studie Avian Biology. 